\title{
Legislació i estrangeria a l'Estat espanyol (1985-2005) Anàlisi del procés de normalització de treballadors estrangers
}

\author{
Marc Sabadí Brugués \\ Núria Marzo Cabero
}

Universitat Autònoma de Barcelona. Departament de Sociologia

Grup d'Estudis d'Immigració i Minories Ėtniques

08193 Bellaterra (Barcelona). Spain

marc.sabadi@campus.uab.es

nuria.marzo@campus.uab.es

\section{Resum}

La present nota d'investigació presenta els aspectes clau de l'evolució històrica de la legislació espanyola en relació a l'estrangeria. Partint de la llei del 1985 fins al moment actual, s'analitzen els efectes d'aquest marc legal sobre les diferents esferes de la comunitat immigrada (estatal, mercantil, familiar i relacional). D'aquesta manera es percep com es crea i s'estructura un nou eix de desigualtat: la desigualtat per ètnia. Dins d'aquest context, més concretament, es descriuen i s'analitzen els principals efectes i limitacions de la implementació del nou reglament i la regularització extraordinària duta a terme entre els mesos de febrer i maig del 2005.

Paraules clau: llei d'estrangeria, immigració, mercat de treball, procés de normalització, desigualtat.

Abstract. Foreign law and immigration at Spain (1985-2005). Analysis of the foreign workers normalization process

This investigation note shows the historical evolution's main points of the Spanish legislation with regard to the alien status. The effects of this legal framework to the different spheres of the immigrant community (estate, laboural, familiar and relational) are analysed since the act of 1985 to the current moment. With this analysis it is perceived the way how a new kind of inequality is created and structured: the ethnic inequality. Specifically on this matter, the main effects and limitations of the new rules implementation and the extraordinary regularization carried out between February and May of the year 2005 are described and analysed.

Key words: law of aliens, immigration, labour market, normalization process, inequality.

\section{Sumari}

1. Les lleis d'estrangeria a l'Estat espanyol

2. Efectes de la legislació sobre immigració
4. Efectes i limitacions del procés de normalització

Bibliografía

3. Descripció del Reglament 
El debat públic sobre la qüestió de la immigració es va centrar, l'any 2005, al voltant del nou reglament de la Llei d'estrangeria, que va presentar, com a novetats principals, la flexibilització dels mecanismes d'accés regular al mercat de treball i l'anunci de mesures més estrictes de control a l'economia submergida. Juntament amb el nou procés «extraordinari» de regularització, les autoritats van afrontar, així, la insostenible situació que suposava l'existència d'una enorme bossa de persones en situació irregular.

Per fer comprensible aquesta situació, cal remuntar-se a la configuració històrica de l'entramat legislatiu espanyol pel que fa a la qüestió de l'estrangeria, i a l'efecte que aquest marc normatiu ha tingut a l'hora de crear un nou eix de desigualtat: la desigualtat per ètnia. Posteriorment, procedirem a descriure els principals elements del nou reglament de la Llei d'estrangeria per, finalment, incidir en els efectes i les limitacions d'aquest, tenint en compte que s'insereix en un marc legislatiu preexistent. Per últim, elaborarem un repàs analític de les tramitacions dels expedients del procés de normalització dels treballadors estrangers residents a l'Estat espanyol.

\section{Les lleis d'estrangeria a l'Estat espanyol}

La regulació de la qüestió de l'estrangeria s'ha portat a terme a l'Estat espanyol mitjançant quatre lleis: la Llei 7/1985, la Llei Orgànica 4/2000, les reformes 8/2000 i la Llei de 2003.

El punt de partida sobre el qual es faran els canvis legals posteriors és la Llei 7/1985, més coneguda com la Llei d'estrangeria. En aquest moment, la immigració encara no és un fenomen notable a l'Estat espanyol i, per aquest motiu, la mateixa llei respon més a les exigències de convergència de la Unió Europea que no pas a la realitat social espanyola. Això no obstant, tant la Llei com el seu reglament fixen els procediments que l'estranger ha d'acomplir per entrar a l'Estat espanyol i obtenir els permisos de residència i de treball ${ }^{1}$, així com les sancions per a qui no compleixi les condicions requerides. D'aquesta manera, i per primer cop, es configura un marc de referència per diferenciar la situació dels immigrants legals dels il.legals, ja que, fins a la Llei d'estrangeria, els «sense papers» no tenien la sensació d'infringir cap norma, sensació que es reforça pel fet de ser, a partir de llavors, perseguits per les autoritats.

1. Estructura legal dels permisos de treball:

1. Permisos de treball per compte d'altri:

Permís "A»: durada màxima de 9 mesos. Per a activitats de temporada o estacionals. No renovable.

Permís «B»: durada màxima d'1 any. Per a activitat i àmbit geogràfic determinats. Renovable.

Permís "C»: 5 anys de durada. Per treballar en qualssevol activitat i àmbit geogràfic. Renovable.

2. Permisos de treball per compte propi:

Permís «D»: durada màxima d' 1 any. Pot atorgar-se per a una activitat determinada. Permís «E»: 5 anys de durada. Sense limitacions geogràfiques. Renovable. 
Per poder treballar legalment, l'estranger ha d'aconseguir un permís de treball de durada limitada, la sol.licitud del qual és simultània a la sol-licitud del permís de residència. Però perquè siguin concedits aquests permisos, cal haver entrat legalment a l'Estat espanyol amb un visat de residència i de treball, així com disposar d'una oferta laboral prèvia per part d'un empresari espanyol. A més, la validesa de la proposta de contracte queda supeditada a la «situació nacional d'ocupació», és a dir, que no hi hagi treballadors espanyols aturats en l'activitat proposada i a la zona geogràfica on es pretén treballar. Així, aquests criteris provoquen que sigui enormement difícil entrar legalment en el territori estatal.

Per altra banda, existeix una clara diferència entre els permisos més estables $(\mathrm{C} \mathrm{i} \mathrm{E})$, que es renoven quinquennalment i de manera pràcticament automàtica, i els més inestables (A, B i D), la renovació dels quals s'ha de dur a terme anualment. Existeixen, a més, preferències per a la concessió de permisos de treball, entre les quals destaquen: tenir ascendència o familiars espanyols a l'Estat espanyol, el temps de residència a l'Estat espanyol i el fet de ser d'Iberoamèrica, de Filipines, d'Equador, d'Andorra, de Gibraltar o d'origen sefardita.

La Llei 7/1985 és, doncs, un document parcial que se centra en les fases inicials de la immigració (creuament de fronteres, entrada, documentació, expulsió) i on s'opta per un règim d'alta discrecionalitat per part de l'Administració, amb la mirada posada en la capacitat de control i de contenció dels fluxos migratoris: la immigració és vista com un fenomen que afecta els nostres veïns europeus i és, per aquest motiu, que el sistema de sancions és el nucli fonamental de la Llei. Tanmateix, cal ubicar l'Estat espanyol com a «frontera d'Europa» i en el marc dels tractats de Schengen (1985) i Maastricht (1993), destinats a consolidar un espai de ciutadania europea i limitar alhora la circulació dels no comunitaris.

Durant la dècada dels anys noranta, es pren consciència de la presència estable d'immigrants a l'Estat i es comencen a establir diverses mesures. La manifesta ineficàcia de les vies ordinàries per regularitzar la força de treball immigrada provoca que, els anys 1991 i 1996, s'obrin processos extraordinaris per regularitzar les grans bosses d'estrangers indocumentats que s'havien format a l'Estat espanyol. Així, el 1996 es reforma el reglament i s'hi incorporen millores com ara el "permís de treball permanent", l'establiment de la universalització del dret a l'ensenyament bàsic, obligatori i gratuït i el dret a rebre atenció mèdica urgent en igualtat de condicions que els nacionals, indiferentment de l'estatus legal de l'estranger. Amb tot, se segueix sense regular el dret a l'habitatge.

Amb la Llei 4/2000, s'obre una nova etapa, quan les autoritats es plantegen com a objectiu bàsic la integració social dels immigrants. El nou text incorpora una sèrie de drets que eren ignorats per la llei anterior i que tan sols es poden exercitar amb l'empadronament municipal. Alguns d'aquests nous drets són: el dret de reunió i de manifestació, el dret d'associació, de sindicació i de vaga, el dret d'assistència sanitària i el dret als serveis i a les prestacions socials 
bàsics. Tot i així, el dret a vot en les eleccions municipals segueix sense ser reconegut. Paral-lelament, s'hi introdueix una nova via (regularització singular permanent), mitjançant la qual l'estranger que pugui acreditar l'estada de dos anys en territori espanyol, que estigui empadronat i que tingui una oferta de treball quedarà regularitzat. A més, el dret a la reagrupació familiar es concedeix des del primer any de residència, amb un permís independent del moment inicial per superar possibles problemes de dependència del cònjuge. D'aquesta manera, s'introdueix un principi d'igualtat progressiva, cosa que comporta un canvi qualitatiu, encara que es manté el model d'immigrant econòmic i treballador de temporada, sempre sota preferència nacional.

Això no obstant, però, aquesta llei tan sols va ser vigent un any i no va arribar a tenir cap reglament, ja que, al març del 2000, el Partit Popular guanyà les eleccions, aquest cop amb majoria absoluta, i va fer de la immigració i de "l'efecte crida» que provocava la llei anterior, un dels seus cavalls de batalla principals. D'aquesta manera, al desembre del 2000, s'aprovava una nova llei d'estrangeria.

Es tracta de la Llei 8/2000, base del règim actual, que pot considerar-se una contrareforma (De Lucas, 2000) pel que fa als drets dels immigrants residents a l'Estat espanyol: es recupera la residència legal com a requisit indispensable per a la concessió de determinats drets (excepte l'assistència sanitària), de manera que l'empadronament deixa de ser suficient per poder tenir-hi accés. La nova normativa també amplia de dos a cinc anys el període de residència necessari per obtenir el permís de residència. A més, tot i que se segueix reconeixent el dret al reagrupament familiar, se suprimeix el dret al familiar reagrupat per obtenir permís de residència independent, de manera que la seva situació administrativa (i, per tant, els seus drets) seguirant dependent de la persona reagrupant. Per altra banda, s'incrementen les sancions en allò que fa referència al tràfic il.legal d'immigrants i a la contractació de treballadors estrangers sense permís.

Finalment, l'any 2003, té lloc una nova reforma de la Llei d'estrangeria. Amb aquesta, els visats serveixen per obtenir permís de residència i de treball, i tot estranger que aconsegueix visat i oferta de feina al país d'origen, obté també el permís de residència. Pel que fa a les mesures de control, es tornen a augmentar les sancions sobre les màfies que trafiquen amb immigrants. Paral.lelament, es reforça el control sobre les persones immigrades a través de la coordinació permanent entre l'Institut Nacional d'Estadística i el Registre Central d'Estrangers de la Policia. O sigui, amb motiu de facilitar-ne el control (i l'expulsió, si escau), s'exigeix que els immigrants renovin periòdicament els permisos de residència.

Aquesta reforma, aprovada amb els vots de populars i socialistes, suposa un enduriment de la normativa sobre immigració, intenta facilitar i simplificar els tràmits per entrar a treballar legalment a l'Estat espanyol, alhora que endureix el control sobre la immigració irregular i promou les expulsions. 


\section{Efectes de la legislació sobre immigració}

Com a conseqüència de les polítiques aplicades al llarg d'aquests anys en matèria d'immigració, s'està traçant un nou eix de desigualtat a l'Estat espanyol: la desigualtat per origen nacional, directament vinculada a la desigualtat per ètnia, que incideix en diferents àmbits o esferes.

\section{Esfera estatal}

En aquesta esfera, és el propi aparell administratiu en l'exercici d'aplicació de les lleis d'estrangeria qui traça la divisió entre ciutadans i no ciutadans. En aquesta gradació de ciutadania, cal distingir-hi tres categories principals: ciutadans europeus comunitaris, estrangers extracomunitaris en situació regularitzada i estrangers extracomunitaris en situació irregular. L’accés als drets dels primers és garantit pels tractats de construcció de la ciutadania europea, en igualtat de condicions que els ciutadans espanyols pel que fa a prestacions socials, i amb dret a vot a les eleccions municipals. En canvi, els immigrants extracomunitaris no disposen dels drets bàsics, sinó que es troben en situació regularitzada.

\section{Esfera laboral}

Els obstacles que la normativa vigent imposa per obtenir i mantenir la situació legal regularitzada, provoquen l'acumulació d'importants contingents d'immigrants no comunitaris que busquen feina i que en troben dins l'anomena$\mathrm{da}$ «economia submergida». La gran dificultat en la qual es troben molts immigrants a l'hora d'intentar obtenir el permís per vies ordinàries fa que, a la pràctica, siguin les regularitzacions extraordinàries els autèntics instruments utilitzats per oficialitzar la situació laboral de l'immigrant extracomunitari (Alegre, a Adelantado, 2000).

Un cop el treballador obté el permís de treball, se li reconeix la igualtat de condicions de vida i laborals respecte als espanyols, exceptuant-ne els drets polítics. Com ja hem esmentat, només l'estranger comunitari empadronat en un municipi pot exercir el seu dret a vot a les eleccions municipals. Per tant, es crea una forta dependència del patró, ja que, si es queda sense feina, no tan sols perd els ingressos, sinó que el seu estatus legal i, per tant, els seus drets, també depenen del seu estat ocupacional. De la mateixa manera, també perd el permís de residència i pot ser expulsat del país. D’aquí ve la gravetat del fet que la discriminació laboral al treballador estranger no estigui tipificada com a delicte ex profeso, a diferència d'altres discriminacions (gènere, edat...), ja que el seu estatus legal depèn del seu estatus ocupacional.

$\mathrm{Cal}$ ser conscients que determinats àmbits ocupacionals acullen amb els braços oberts la força de treball immigrada irregular, sobretot «aquelles branques de l'economia que registren una intensitat més gran en l'aplicació del treball i que disposen d'un escàs marge per l'increment de la productivitat d'aquest 
treball», registren «una creixent informalització del treball en violació de les regulacions legals» (Mingione, 1993; a Adelantado, 2000). Ens referim, sobretot, a ocupacions dins els sectors com ara la construcció, l'agricultura i el servei domèstic, que clarament es beneficien de les conseqüències de la política d'immigració.

Per altra banda, el sistema de quotes o de contingents anuals que prioritzen la «situació nacional d'ocupació» és un instrument prou útil per institucionalitzar el que Wallerstein (1991) anomena l'«etnització del mercat laboral», de manera que es reserva un determinat nínxol ocupacional, dins el segment secundari, per a la força de treball immigrada. Aquest sistema de quotes funciona també com a sistema de legitimació èticament dubtós però socialment eficient: l'argument de la bondat dels immigrants pel seu grau més elevat d'acceptació, ja que ocupen llocs de treball que els treballadors espanyols consideren «indesitjables».

En definitiva, la situació de bona part dels immigrants a l'Estat espanyol, com a conseqüència de l'aplicació de les polítiques d'immigració, és d'una gran precarietat. Bé sigui perquè no estan regularitzats pel que fa a la seva situació laboral o residencial o perquè treballen sota l'amenaça constant de la necessitat de renovar els permisos corresponents.

\section{Esfera familiar}

La dificultat, la complexitat, les condicions i el temps que requereix el procediment pel qual els immigrants poden efectuar el reagrupament familiar té conseqüències en l'estructura familiar dels estrangers residents a l'Estat espanyol. També, en aquest cas, la política realitzada té més de política d'estrangeria que no pas de política d'immigració i d'integració. El tracte institucional que rep la família immigrada respon més a la consideració de la immigració com un fenomen transitori i provisional.

Per una banda, abunden les famílies desestructurades en les quals falten membres i, per l'altra, també apareixen nombroses famílies «sense trajectòria», és a dir, amb absència de contacte regular entre els seus familiars. Com a conseqüència de les dificultats que representa reunir les condicions per realitzar el reagrupament familiar, el temps passa i, en cas d'aconseguir el reagrupament, apareixen possibles problemes derivats de la llarga absència d'una relació constant i consolidada entre els familiars. Aquest fet és especialment greu quan els reagrupants són infants de curta edat. A més, és una circumstància que «afegeix més incertesa al procés de formació d'una unitat familiar estable com requereix la mateixa dinàmica de la integració social a la nostra societat» (Alegre, a Adelantado, 2000, p. 392).

Un altre efecte, potser menys visible, es deriva de la ideologia familiar implícita en la llei que només accepta la família nuclear com a únic model possible. Això implica que no es poden reagrupar completament famílies polígames, ni tan sols es poden reagrupar familiars col-laterals. Si es té en compte que moltes societats tenen estructures diferents de la família nuclear, es poden 
comprendre les implicacions que té aquest biaix ideològic per a molts immigrants.

Totes aquestes circumstàncies poden fer augmentar el desig de retorn de l'immigrant $i$, amb freqüència, la poca o nul-la identificació amb la societat receptora, fets que minven la voluntat d'implicació i d'integració en aquesta.

Per altra banda, des de la reforma de la Llei 8/2000, l'estatus legal del membre reagrupat està absolutament al servei de la situació administrativa del reagrupant, en no disposar d'un permís de residència independent des del moment que arriba al territori espanyol. Aquesta situació pot provocar problemes de dependència del cònjuge, normalment dona, respecte al reagrupant.

\section{Esfera relacional}

Un altre efecte destacable de la política d'immigració és la gran fragmentació que pateix la classe treballadora immigrant. La laberíntica estructura dels permisos de treball sumada a l'existència de preferències per als col-lectius d'immigrants "històrics», en detriment de l'entrada, l'estabilitat i la integració de la «nova immigració», majoritàriament procedent del Magrib, fa augmentar aquesta fragmentació. Aquesta circumstància, i el fet que la irregularitat administrativa suposi la negació del dret a intervenir en la vida pública, és a dir, el dret a reunió i associació i el de sindicació i vaga, provoca que sigui extraordinàriament difícil per als immigrants portar a terme accions de lluita col.lectiva.

A més, la falta de drets, la condició d'infraciutadà, la incapacitat de participar en la vida pública, les dificultats per reagrupar la família i la dificultat per inserir-se en el mercat laboral de manera estable, poden fer augmentar el desig de retorn i el grau més baix d'implicació en les institucions de la societat receptora, cosa que va en detriment de la tan desitjada integració dels nouvinguts. Aquesta sensació de desemparament general fa que l'immigrant busqui llaços de solidaritat dins l'esfera comunitària, dins la seva comunitat ètnica, cosa que afavoreix la tendència a la "guetització».

L'argument que són necessàries unes polítiques d'immigració restrictives per evitar «l'efecte crida» es mostra fal-laç, ja que l'enduriment de la legislació, cada cop més orientada al control i no a la integració sociocultural, no fa disminuir el nombre d'immigrants i no conté els fluxos. L'impuls per millorar les seves condicions de vida i les desigualtats econòmiques i socials entre els països fa imparable la immigració, bé sigui pel desconeixement que els immigrants tenen de la legislació vigent, bé sigui pel càlcul racional dels costos que pot suposar enfront dels beneficis i les probabilitats de tirar endavant (Solé, 2005).

\section{Descripció del reglament}

Com hem pogut comprovar, tot aquest marc jurídic i normatiu genera incertesa, ja que esdevé un cos legal complex que necessita uns continguts més sim- 
ples i clars. Enfront d'aquesta situació, el Govern del PSOE ha intentat fer un gir en la política i la legislació referents a l'estrangeria, per tal d'intentar donar una solució al gran nombre de treballadors que es troben en situació irregular a l'Estat espanyol i que, majoritàriament, encara resten submisos a l'economia submergida. Per aquests motius, s'ha dut a terme la redacció i l'aplicació del nou Reial Decret 2393/2004, de 30 de desembre, pel qual s'aprova el reglament de la Llei Orgànica 4/2000, d'11 de gener, sobre drets i llibertats dels estrangers a Espanya i la seva integració social, del qual ens n'interessa la disposició transitòria tercera, que fa referència al procés de normalització dels treballadors estrangers que resideixen a l'Estat espanyol. Aquest és un procés de normalització a través del qual es permet que un individu romangui a l'Estat espanyol, sempre i quan compleixi uns requisits legals.

Abans d'explicar quins són els continguts principals del procés de normalització, hem de considerar els diversos elements que s'han tingut en compte a l'hora de redactar-lo. En primer lloc, cal dir que s'han considerat les opinions de diversos col-lectius implicats en el tema, com ara sindicats, organitzacions empresarials, col.legis professionals, etc., i és important destacar la consideració per part de l'Informe del Consell Econòmic i Social sobre la immigració i el mercat de treball a Espanya ${ }^{2}$. Així doncs, l'aplicació del Reial Decret 2393/2004 pretén prioritzar la immigració legal i continuar la persecució de la immigració irregular a través de la lluita contra l'economia submergida, és a dir, es pretén incidir en l'ordenació del mercat laboral per tal d'evitar la perpetuació de relacions laborals irregulars.

Més enllà de fer una descripció detallada del contingut del Reial Decret, hem volgut destacar els elements principals del procés de normalització ${ }^{3}$, per tal de poder-ne veure, posteriorment, els efectes i les limitacions. Per tant, d'entrada, hem de dir que fixa els procediments per a la regularització d'aquells immigrants que treballen sense la possessió d'un contracte laboral i que fa sis mesos que estan empadronats a l'Estat espanyol. Els estrangers que es poden acollir a aquest procés, han d'estar empadronats abans del 7 d'agost de 2004, no han de tenir antecedents penals a l'Estat espanyol ni en el seu país d'origen o on hagin residit en els cinc anys anteriors a la sol-licitud. També se'ls podrà exigir la titulació degudament homologada que els habiliti per treballar en el lloc que ocuparan. L'empresa ha d'estar vàlidament inscrita en la Seguretat Social i no ha d'haver incorregut en cap de les causes de denegació d'autoritzacions. Si ens fixem en el contingut de la disposició transitòria, cal dir que

2. Resum de l'Informe en el Dictamen sobre el Proyecto de Real Decreto por el que se aprueba el Reglamento de la Ley Orgánica 4/2000, de 11 de enero, sobre Derechos y Libertades de los Extranjeros en España y su Integración Social (Ministerio de Trabajo y Asuntos Sociales. Secretaría de Estado de Inmigración y Emigración).

3. Informació extreta de la Disposició Transitòria Tercera del Proyecto de Reglamento de la Ley Orgánica 4/2000, de 11 de enero, sobre Derechos y Libertades de los Extranjeros en España y su Integración Social (Ministerio de Trabajo y Asuntos Sociales. Secretaría de Estado de Inmigración y Emigración). 
tot aquell qui vulgui contractar un estranger que es trobi en situació irregular, ha de garantir-li una ocupació que duri, almenys, sis mesos. Tot i així, aquesta regla té tres excepcions: els sectors de l'hosteleria i la construcció han de garantir sis mesos en un període d'un any, el sector agrícola pot reduir la durada a tres mesos i, en el servei domèstic, també ha de ser de sis mesos, però és l'únic cas en el qual ha de ser el propi estranger qui sol-liciti l'autorització a partir de diferents contractes que han de sumar una activitat setmanal de, com a mínim, trenta hores.

Així doncs, els passos que cal seguir en el procés de normalització són els següients: presentació de la sol-licitud, per part de l'empresari, juntament amb el contracte laboral degudament firmat per totes dues parts i, seguidament, la possibilitat de resolució administrativa favorable o desfavorable. Si la resolució administrativa és desfavorable, és a dir, els requisits no es compleixen, l'empresari té la possibilitat d'interposar un recurs, i si la resolució és favorable, l'autorització de residència i de treball està condicionada, ja que la condició indispensable següent és donar o no d'alta el treballador a la Seguretat Social en el termini d'un mes, per tal que l'autorització comenci el seu període de vigència. Si no es produeix l'afiliació, la resolució queda sense efecte i l'estranger es troba en situació irregular; si es produeix l'alta del treballador a la Seguretat Social, l'autorització entra en vigor per un any i, llavors, el treballador ha de sol.licitar la targeta d'identitat de l'estranger (TIE), per tal de situarse legalment a l'Estat espanyol.

D'altra banda, a partir de la finalització del període transitori de tres mesos, els immigrants han pogut regularitzar la seva situació per dues vies extraordinàries: la de l'arrelament social i la de l'arrelament laboral. La primera via consisteix a demostrar més de tres anys de residència a l'Estat i l'oferta d'un contracte temporal, i la segona via té per objectiu la presentació de la documentació d'un any de treball i dos de residència.

Un altre plantejament del Reial Decret ha estat l'aclariment que ha fet dels tres sistemes d'entrada dels treballadors al nostre país: el de règim general, el del contingent de treballadors que es necessiten i el de les ofertes de treball de temporada. A més, el procés de reagrupació familiar s'ha pogut sol.licitar juntament amb la sol-licitud de la renovació de l'autorització, és a dir, de sis a dotze mesos abans i, a més, s'ha exigit un determinat rigor al sol-licitant perquè demostri que realment pot fer venir els seus familiars, és a dir, ha de tenir una estabilitat econòmica determinada i un habitatge en bones condicions.

\section{Efectes i limitacions del procés de normalització}

Després de fer una breu ullada als continguts principals del procés de normalització, hem d'incidir en els efectes i en les limitacions que ha establert. En principi, no s'ha d'oblidar que el procés de normalització es tracta d'una mesura conjuntural i provisional duta a terme per tal de donar resposta a una situació urgent: l'enorme bossa de treballadors estrangers indocumentats. Per això, es realitza sense modificar el marc jurídic de l'Estat relatiu als temes d'estrangeria. 
No es pot negar que hagi fet emergir una part de l'economia submergida existent i que els treballadors que s'hagin adaptat al procés de normalització puguin gaudir dels drets de ciutadania que li són atorgats per llei. Aquesta situació els ha permès gaudir d'un estret marge per negociar les condicions laborals del seu lloc de treball. Tot i així, l'aparent estabilitat jurídica no evita que els treballadors estrangers estiguin encara subjectes a una gran inestabilitat laboral com a conseqüència de la total dependència del mercat laboral per al manteniment i la renovació dels permisos, fet que pot afavorir que alternin la inserció en l'economia formal amb l'economia submergida.

Per altra banda, hem de considerar el poder de l'empresari en aquest procés, ja que és el subjecte que ha dut a terme l'acció de presentar la sol.licitud (si bé no cal que sigui en persona) per tal de normalitzar la situació del seu treballador (que sí que ha d'anar-hi). Tot i que s'hagin realitzat dures inspeccions a les empreses que no han normalitzat la situació irregular dels seus treballadors, existeix la possibilitat i el fet que l'empresari els hagi despatxat en comptes d'afrontar les conseqüències i/o obligar-se a contractarlos formalment, és a dir, hi ha empresaris que se senten còmodes amb els seus treballadors en situació irregular, tant pel que fa als impostos que s'estalvien de pagar com per les males condicions laborals que els poden imposar. Així, tal com ha passat en d'altres regularitzacions (Solé, 2001), pot succeir que aquells empresaris que hagin contractat formalment els seus treballadors continuïn assalariant-los il.legalment un cop s'ha consolidat el procés $\mathrm{i}$, com ja hem esmentat, que els empresaris facin ús de l'estratègia d'acomiadament del treballador. En aquest sentit, podem dir que la regularització ha permès a la majoria d'empreses de treball temporal rentar-se les mans d'aquesta responsabilitat, tot i la gran quantitat d'estrangers que treballen a partir d'aquestes.

En relació amb els requisits, podem dir que el fet que s'exigeixin sis mesos d'estada anteriors a l'entrada en vigor de la norma, suposa una limitació gratuïtament restrictiva, ja que, a partir de la llei 8/2000, la policia accedeix a les dades del padró municipal per tal de conèixer quines són les persones que es troben en situació irregular, fet que va portar molts irregulars a no empadronarse. Només abans de setze dies per a la finalització del termini per presentar la documentació, es va modificar aquest requisit, després de múltiples peticions d'associacions d'immigrants, del Defensor del Poble i del Consell General d'Advocacia s'acceptà l'aportació de «documents fefaents» per provar l'estada a l'Estat espanyol abans del 7 d'agost de 2004.

Un altre aspecte problemàtic és el que fa referència al certificat d'antecedents penals, ja que, per una banda, tots els estrangers procedents de països dels quals han marxat il.legalment han tingut dificultats per obtenir el document acreditatiu i, per l'altra, és molt probable que, en cas que l'hagin obtingut, el procés hagi estat lent i hagi sobrepassat els tres mesos de termini del procés de normalització. Així, un problema que també ha aparegut és la durada del termini del procés, ja que esdevé massa breu i no ha estat suficient en molts casos. 
Això no obstant, aquest procés ha fet que molts treballadors hagin sortit de l'economia submergida. Les dades presentades pel Ministeri de Treball y Afers Socials ${ }^{4}$ sobre el procés de normalització, han estat les següents: el balanç final del procés és de 691.655 sol-licituds presentades de les quals n'han autoritzat $572.961 \mathrm{com}$ a positives i $115.178 \mathrm{com}$ a negatives. Tanmateix, les comunitats autònomes amb un nombre més elevat de sol.licituds han estat la Comunitat de Madrid, Catalunya i la Comunitat Valenciana. Seguint amb les dades, cal veure com s'han resolt 688.139 autoritzacions $(99,49 \%)$ i encara en queden $3.516(0,51 \%)$ en tràmit gràcies a la manca de recursos humans de l'Administració. Així, podem dir que un $83,26 \%$ del total d'expedients resolts, han estat acceptats. Però, com ja hem explicat en la descripció del procés, els treballadors s'han de donar d'alta a la Seguretat Social per tal de poder, posteriorment, obtenir la targeta d'identitat de l'estranger (TIE). Les dades que fan referència a l'alta a la Seguretat Social, 548.720 altes, ens mostren que hi ha hagut més homes $(55,86 \%)$ que dones $(44,13 \%)$ que han dut a terme aquest acció. Igualment, els treballadors estrangers que han sol-licitat més les autoritzacions i l'alta a la Seguretat Social han estat els d'origen equatorià, romanès o marroquí. Per altra banda, si ens fixem en els expedients resolts i en les altes per règim, podem veure com, en el sector de la llar, s'ha registrat un $33,46 \%$, un $20,39 \%$ en la construcció, un $14,15 \%$ en el sector agrari i un $9,72 \%$ en l'hosteleria. Finalment, si observem les dades en funció de l'edat dels treballadors, podem veure que un 60,39\% dels estrangers amb l'autorització i l'alta a la Seguretat Social tenen entre 25 i 39 anys. Després d'observar aquestes dades, podem dir que, gràcies a aquest procés, hi ha hagut molts irregulars que han normalitzat la seva situació, però que molts altres milers continuaran estant en la mateixa situació. A més, els efectes positius del procés de normalització disminuiran a mitjà termini, ja que, a l'hora de demanar la renovació dels permisos de treball i residència, el treballador estranger es troba en la mateixa situació.

Tot i que el Govern espanyol i els sindicats incitin els treballadors immigrants a denunciar els empresaris que no els han permès regularitzar-se, és evident que una gran majoria no ho pot fer, perquè no podrà demostrar la seva relació laboral irregular amb l'empresari en qüestió. Per altra banda, els efectes de les anunciades inspeccions han estat i són sempre limitats. Amb això, aquest reglament reforça la concepció del subjecte immigrat definida al marc normatiu vigent mitjançant l'equació inmigrant = treballador. Es concep la immigració exclusivament com a mà d'obra, i tots els seus drets (mai igualats als dels nacionals) depenen de la seva inserció al mercat laboral formal. Així continua la situació de dependència extrema de l'estranger respecte a la possessió d'un contracte de treball. Així doncs, finalitzat aquest procés, alguns estrangers que ja treballaven, han estat contractats amb tots els ets i uts; uns altres que també treballaven, han estat acomiadats, i n'hi haurà uns altres que segui- 
ran treballant en les mateixes condicions. La gran bossa d'indocumentats s'ha reduït, però continua existint fins a la pròxima regularització.

A manera de proposta, pensem que s'hauria de dur a terme un estudi on participessin aquelles perspectives disciplinàries que disposen de les categories d'anàlisi necessàries per englobar el conjunt de situacions relatives a la immigració, per tal de canviar la situació legislativa actual i, consegüentment, social i política, sense haver d'estar sobrevivint a partir de processos de normalització que no acaben d'afrontar i que ajuden a reproduir la realitat que ens envolta davant la immigració.

\section{Bibliografia}

Alegre, M. A. (2000). «Las políticas inmigratorias». A: Adelantado, J. (coord.). Cambios en el estado del bienestar. Políticas sociales y desigualdades en España. Antraxyt: Icaria.

Dictamen del Consejo Económico i Social (CES) sobre el Proyecto de Real Decreto por el que se aprueba el Reglamento de la Ley Orgánica 4/2000, de 11 de enero, sobre Derechos y Libertades de los Extranjeros en España y su Integración Social (ple ordinari de 24 de novembre de 2004).

LuCAS. J. de (2003). Blade Runner: el Derecho, guardián de la diferencia. València: Tirant lo Blanch.

- (2003). «Una oportunidad perdida para la política de inmigración. La contrarreforma de la ley 8/2000 en España». A: LUCAS, Javier de; MESTRE, Ruth; SOLANES, Ángeles; PEÑA, Salomé (coord.). Inmigrantes: una aproximación jurídica a sus derechos. València: Germania.

Pajares, M. (2004). «La eficacia de la regularización». El Periódico, 23 de desembre. «Reglamento de la Ley Orgánica 4/2000 de 11 de enero, sobre derechos y libertades de los extranjeros en España y su integración social». $B O E$, núm. 6, 7 de gener de 2005.

SOlÉ, C. (2001). El impacto de la inmigración en la economía y en la sociedad receptora. Barcelona: Anthropos.

- (2005). Efectos no deseados de la legislación sobre inmigración. Barcelona: UAB. WALERSTEIN, I. (1991). Raza, nación y clase. Madrid: IEPALA. 